\title{
Ceruloplasmin Oxidation, a Feature of Parkinson's Disease CSF, Inhibits Ferroxidase Activity and Promotes Cellular Iron Retention
}

\author{
Stefano Olivieri, ${ }^{1 *}$ Antonio Conti, ${ }^{1 *}$ Sandro Iannaccone, ${ }^{2}$ Carlo V. Cannistraci, ${ }^{1,7}$ Alessandro Campanella,, 3 \\ Marco Barbariga, ${ }^{1}$ Franca Codazzi, ${ }^{4}$ Ilaria Pelizzoni, ${ }^{4}$ Giuseppe Magnani, ${ }^{5}$ Mariasabina Pesca, ${ }^{1,8}$ Diego Franciotta, ${ }^{6}$ \\ Stefano F. Cappa, ${ }^{2,9}$ and Massimo Alessio ${ }^{1}$ \\ ${ }^{1}$ Proteome Biochemistry, ${ }^{2}$ Clinical Neurosciences, ${ }^{3}$ Italian Institute of Technology Network-Molecular Neuroscience, ${ }^{4}$ Cellular Neurophysiology, \\ ${ }^{5}$ Experimental Neurology Institute, San Raffaele Scientific Institute, I-20132 Milan, Italy, ${ }^{6}$ Laboratory of Neuroimmunology, Istituto di Ricovero e Cura a \\ Carattere Scientifico, National Neurological Institute Mondino, I-27100 Pavia, Italy, ${ }^{7}$ Integrative Systems Biology, Division of Chemical and Life Sciences \\ and Engineering, Division of Applied Mathematics and Computer Sciences and Engineering, Computational Bioscience Research Center, King Abdullah \\ University of Science and Technology, Thuwal 23955-6900, Kingdom of Saudi Arabia, ${ }^{8}$ Farmaceutical Sciences, Salerno University, I-84084 Fisciano, \\ Salerno, Italy, and ${ }^{9}$ Vita-Salute San Raffaele University, I-20132 Milan, Italy
}

Parkinson's disease is a neurodegenerative disorder characterized by oxidative stress and CNS iron deposition. Ceruloplasmin is an extracellular ferroxidase that regulates cellular iron loading and export, and hence protects tissues from oxidative damage. Using two-dimensional electrophoresis, we investigated ceruloplasmin patterns in the CSF of human Parkinson's disease patients. Parkinson's disease ceruloplasmin profiles proved more acidic than those found in healthy controls and in other human neurological diseases (peripheral neuropathies, amyotrophic lateral sclerosis, and Alzheimer's disease); degrees of acidity correlated with patients' pathological grading. Applying an unsupervised pattern recognition procedure to the two-dimensional electrophoresis images, we identified representative pathological clusters. In vitro oxidation of CSF in two-dimensional electrophoresis generated a ceruloplasmin shift resembling that observed in Parkinson's disease and co-occurred with an increase in protein carbonylation. Likewise, increased protein carbonylation was observed in Parkinson's disease CSF, and the same modification was directly identified in these samples on ceruloplasmin. These results indicate that ceruloplasmin oxidation contributes to pattern modification in Parkinson's disease. From the functional point of view, ceruloplasmin oxidation caused a decrease in ferroxidase activity, which in turn promotes intracellular iron retention in neuronal cell lines as well as in primary neurons, which are more sensitive to iron accumulation. Accordingly, the presence of oxidized ceruloplasmin in Parkinson's disease CSF might be used as a marker for oxidative damage and might provide new insights into the underlying pathological mechanisms.

\section{Introduction}

Parkinson's disease (PD) is characterized by a progressive neuronal degeneration in specific areas of the CNS caused, inter alia, by oxidative damage, excitotoxicity, and inflammation (Dawson and Dawson, 2003; Litvan et al., 2007a,b).

Oxidative stress arises when the production of toxic reactive oxygen species (ROS) is disproportionate to scavenging factors.

Received July 22, 2011; revised Aug. 29, 2011; accepted Sept. 21, 2011.

Author contributions: F.C., S.F.C., and M.A. designed research; S.O., A. Conti, S.I, A. Campanella, M.B., F.C., I.P., G.M.,

M.P., and D.F. performed research;S.O., C.V.C., S.F.C., and M.A. analyzed data; S.O., D.F., and M.A. wrote the paper.

This work was supported by Fondazione Cariplo (Nobel-Guard project) and by Ministry of Health Grant RF07-ALS (M.A.). We thank Prof. G. Comi (Experimental Neurology Institute, San Raffaele Scientific Institute, Milan, Italy) and Dr. L. Piccio (Department of Neurology, Washington University School of Medicine, St. Louis, M0) for critical discussion and suggestions, and J. Martinez Fraile (Erasmus student, Oviedo University, Oviedo, Spain) who contributed to some experiments.

*S.O. and A. Conti contributed equally to this work.

This article is freely available online through the J Neurosci Open Choice option.

Correspondence should be addressed to Dr. Massimo Alessio, Proteome Biochemistry, San Raffaele Scientific Institute, via Olgettina 58, I-20132 Milan, Italy. E-mail: m.alessio@hsr.it.

S. Olivieri's present address: Neurobiology, Biozentrum, University of Basel, Klingelbergstrasse 50/70, CH-4056 Basel, Switzerland.

DOI:10.1523/JNEUROSCI.3768-11.2011

Copyright $\odot 2011$ the authors $\quad 0270-6474 / 11 / 3118568-10 \$ 15.00 / 0$
Scavenging variously (although not exclusively) manifests as enzymatic activity, as low-molecular-weight antioxidant species and as other forms of protection, such as metal transport systems (Carrí et al., 2003). The correct handling of transition metal ions, like copper and iron, is crucial to such systems, since these metals undergo red-ox reactions, during which ROS can be generated. Iron is the most abundant transition metal in the body. In the brain substantia nigra $(\mathrm{SN})$, the most vulnerable region in $\mathrm{PD}$, there is a high iron concentration (Götz et al., 2004); accordingly, $\mathrm{SN}$ is especially sensitive to oxidative stress. Moreover, the dopamine metabolism of nigral neurons leads to the production of hydrogen peroxide, which in turn can convert to hydroxyl radical when ferrous iron co-occurs (Lotharius and Brundin, 2002). In $\mathrm{PD}, \mathrm{SN}$ neuronal degeneration is related to increases in protein oxidation and in iron concentration (Oakley et al., 2007). Red-ox systems, such as protein-containing metal ions, exploit cyclical changes in their red-ox status as a way to resist oxidative stress. One of these proteins is the copper protein ceruloplasmin (Cp), which is secreted by the liver into plasma, and by cells of the choroid plexus into CSF (Vassiliev et al., 2005). A membranebound glycosylphosphatidylinositol (GPI)-anchored form of Cp 
Table 1. Demographic and clinical features of patients and controls

\begin{tabular}{|c|c|c|c|c|c|c|c|c|c|c|c|c|c|c|c|c|}
\hline & \multicolumn{4}{|l|}{$P D$} & \multicolumn{3}{|l|}{$\mathrm{CN}$} & \multicolumn{3}{|l|}{ ALS } & \multicolumn{3}{|l|}{ PN } & \multicolumn{3}{|l|}{$A D$} \\
\hline & Sex & Age & {$[\mathrm{C}](\mathrm{mg} / \mathrm{ml})$} & $\overline{\text { UPDRS }}$ & Sex & Age & {$[\mathrm{C}](\mathrm{mg} / \mathrm{ml})$} & Sex & Age & {$[\mathrm{C}](\mathrm{mg} / \mathrm{ml})$} & Sex & Age & {$[\mathrm{C}](\mathrm{mg} / \mathrm{ml})$} & Sex & Age & {$[\mathrm{C}](\mathrm{mg} / \mathrm{ml})$} \\
\hline 1 & $M$ & 65 & 0.38 & 17 & $M$ & 70 & 0.37 & $M$ & 61 & 0.32 & $\mathrm{~F}$ & 53 & 0.57 & $M$ & 61 & 0.51 \\
\hline 2 & $\mathrm{~F}$ & 80 & 0.85 & 49 & $\mathrm{~F}$ & 50 & 0.20 & $M$ & 71 & 0.17 & $\mathrm{~F}$ & 60 & 0.35 & $M$ & 70 & 0.44 \\
\hline 3 & $\mathrm{~F}$ & 68 & 0.51 & 40 & $M$ & 71 & 0.38 & $M$ & 63 & 0.28 & $F$ & 69 & 0.75 & $F$ & 78 & 0.19 \\
\hline 4 & $\mathrm{~F}$ & 64 & 0.37 & 47 & $M$ & 62 & 0.16 & $M$ & 64 & 0.27 & $M$ & 74 & 0.26 & $M$ & 78 & 0.46 \\
\hline 5 & $M$ & 71 & 0.36 & 76 & $\mathrm{~F}$ & 53 & 0.25 & $\mathrm{~F}$ & 68 & 0.30 & $M$ & 50 & 1.06 & $F$ & 72 & 0.33 \\
\hline 6 & $M$ & 61 & 0.32 & 61 & $M$ & 63 & 0.85 & $\mathrm{~F}$ & 70 & 0.46 & $\mathrm{~F}$ & 64 & 0.32 & $F$ & 65 & 0.36 \\
\hline 7 & $M$ & 70 & 0.73 & 67 & $M$ & 73 & 0.47 & $\mathrm{~F}$ & 75 & 0.36 & $M$ & 74 & 0.53 & $\mathrm{~F}$ & 58 & 0.35 \\
\hline 8 & M & 70 & 0.39 & 69 & $\mathrm{~F}$ & 72 & 0.40 & $\mathrm{~F}$ & 70 & 0.40 & $M$ & 64 & 0.39 & $M$ & 74 & 0.38 \\
\hline 9 & $M$ & 77 & 0.63 & 52 & $F$ & 50 & 0.19 & $M$ & 61 & 0.27 & $M$ & 80 & 0.41 & $F$ & 63 & 0.26 \\
\hline 10 & $\mathrm{~F}$ & 56 & 0.46 & 42 & $F$ & 77 & 0.50 & $\mathrm{~F}$ & 61 & 0.26 & $\mathrm{~F}$ & 44 & 0.30 & $\mathrm{~F}$ & 74 & 0.45 \\
\hline 11 & $M$ & 56 & 0.30 & 55 & $M$ & 71 & 0.43 & $F$ & 69 & 0.23 & $M$ & 50 & 0.58 & $\mathrm{~F}$ & 62 & 0.53 \\
\hline 12 & $\mathrm{~F}$ & 73 & 0.46 & 41 & $M$ & 68 & 0.32 & $\mathrm{~F}$ & 57 & 0.23 & M & 60 & 0.33 & $\mathrm{~F}$ & 68 & 0.31 \\
\hline 13 & $\mathrm{~F}$ & 66 & 0.60 & 48 & $\mathrm{~F}$ & 63 & 0.18 & $\mathrm{~F}$ & 71 & 0.21 & $M$ & 46 & 0.45 & $M$ & 56 & 0.48 \\
\hline 14 & $M$ & 77 & 0.28 & 27 & $F$ & 77 & 0.51 & $\mathrm{~F}$ & 62 & 0.58 & & & & $F$ & 73 & 0.31 \\
\hline 15 & & & & & $F$ & 60 & 0.30 & $F$ & 62 & 0.82 & & & & & & \\
\hline 16 & & & & & & & & $\mathrm{~F}$ & 76 & 0.30 & & & & & & \\
\hline & $8 \mathrm{M}$ & & & & $7 \mathrm{M}$ & & & $5 \mathrm{M}$ & & & $8 \mathrm{M}$ & & & $5 \mathrm{M}$ & & \\
\hline & $6 \mathrm{~F}$ & & & & $8 \mathrm{~F}$ & & & $11 \mathrm{~F}$ & & & $5 F$ & & & $9 \mathrm{~F}$ & & \\
\hline Mean & & 68.1 & 0.47 & & & 65.3 & 0.37 & & 66.3 & 0.34 & & 60.6 & 0.48 & & 68.0 & 0.38 \\
\hline SD & & 1.98 & 0.17 & & & 9.03 & 0.18 & & 5.63 & 0.16 & & 11.5 & 0.22 & & 7.23 & 0.10 \\
\hline
\end{tabular}

Gender: No statistical differences among groups (Fisher's exact test). Age: No statistical differences among groups (Student's $t$ test). Protein concentration [C]: No statistical differences among groups except for PD versus ALS, $p=0.008$, and PN versus ALS, $p=0.020$ (Mann-Whitney test). [C], CSF total protein concentration.

is expressed by astrocytes and by leptomeningeal cells in the CNS (Mittal et al., 2003). Cp acts as a ferroxidase, one that oxidizes toxic ferrous iron to the nontoxic ferric form (Hellman and Gitlin, 2002). The Cp expressed in the brain likely plays an important role in CNS iron homeostasis and antioxidant defense (Texel et al., 2008). The importance of the protective function of $\mathrm{Cp}$ is demonstrated by aceruloplasminemia patients, in whom brain and liver iron deposition is massive (Harris et al., 1998). Furthermore, $\mathrm{Cp}^{-1-}$ mice CNS shows iron accumulation and increased free radical-mediated damage (Patel et al., 2002). It is therefore possible that changes in CSF Cp expression and/or in protein modification(s), which affect enzymatic activity, may contribute to $\mathrm{PD}$ neurodegeneration by instigating an increase in ferrous iron, which, in turn, may promote the generation of toxic free radicals (Patel et al., 2002; Rathore et al., 2008).

To assess PD Cp for specific modifications, we compared proteomic Cp profiles evidenced in CSF collected from PD patients, healthy subjects, and patients with other neurological diseases, respectively. A heightened acidic Cp profile, the result of $\mathrm{Cp}$ oxidation, distinguished PD patients. Oxidized Cp showed an impairment in ferroxidase activity, which induced an in vitro intracellular iron accumulation in neuronal cell lines, as well as in primary neurons. These findings indicate the analysis of Cp oxidation pattern as a putative PD biomarker and shed light on mechanisms that possibly underlie PD pathophysiology.

\section{Materials and Methods}

Patients. Having secured approval from the ethical review board of the hospital, and informed consent from patients, we collected CSF samples $(0.8-1 \mathrm{ml})$ by means of lumbar puncture. The analyzed groups were as follows: sporadic PD ( $n=14 ; 8$ males and 6 females), sporadic amyotrophic lateral sclerosis (ALS) ( $n=16 ; 5$ males and 11 females), peripheral neuropathies (PN) ( $n=13 ; 8$ males and 5 females), Alzheimer's disease (AD) $(n=14 ; 5$ males and 9 females), and healthy controls $(\mathrm{CN})(n=15$; 7 males and 8 females). Table 1 summarizes the demographic and clinical features of the patients and control subjects enrolled on this discovery study. All patients were at first diagnosis and drug-free. Current criteria for the diagnosis of PD (Italian Neurological Society, 2003), of ALS (Brooks, 1994), and of AD (McKhann et al., 1984) were used for the admission of patients into the study. PN diagnosis was as described by
Conti et al. (2005). The Unified Parkinson's Disease Rating Scale (UPDRS) (Hoehn and Yahr, 1967; Fahn, 1987) was used to grade the disease. ALS and PN samples were from aliquots collected for previous studies (Conti et al., 2005, 2008), while CSF from AD patients derived from the Institute of Experimental Neuroscience Bio-Bank (Institute of Experimental Neuroscience, San Raffaele Scientific Institute). Exclusion criteria consisted of the following: HIV or HCV (hepatitis C virus) seropositivity, the appearance of other neurodegenerative diseases or previous cerebral ischemic events, and severe metabolic disorders (e.g., diabetes). Control CSF was obtained from patients who underwent lumbar puncture on account of a suspected neurological disease and who proved to be normal and free from pathological alterations after complete CSF analysis and thorough clinico-neuroimaging assessment. Sample selection ensured that age and gender distributions were homogeneous with those of the PD patients.

Two-dimensional electrophoresis, Western blot, and image analysis. Immediately after collection, the CSF samples were centrifuged at $4^{\circ} \mathrm{C}$ to eliminate cells, and protein concentrations were determined. The samples were then either immediately processed, or stored after acetone precipitation at $-80^{\circ} \mathrm{C}$ in an $\mathrm{N}_{2}$-supplemented atmosphere to avoid oxidation. Protein samples $(30 \mu \mathrm{g})$ were resuspended in twodimensional electrophoresis (2DE) buffer ( $8 \mathrm{~m}$ urea, $4 \% \mathrm{w} / \mathrm{v}$ CHAPS, 65 mM DTT, $0.2 \%$ v/v IPG buffer 3-10NL, and applied to $7 \mathrm{~cm}$ IPG strips $\mathrm{pH} 3-10 \mathrm{NL}$ (GE Healthcare). The 2DE separations were performed as described by Conti et al. (2008).

Proteins resolved by 2DE or by SDS-PAGE were electrotransferred onto nitrocellulose membranes and Western blot (WB) was performed as described by Conti et al. (2008) with an anti-human Cp antibody (Abcam). Images were acquired by means of a laser densitometer (GE Healthcare), and evaluation of relative abundance of $\mathrm{Cp}$ isoforms consisted in the analysis of optical density normalized to percentage by means of Progenesis PG240 software (Nonlinear Dynamics).

CSF oxidation by treatment with $\mathrm{Fe}$-citrate and $\mathrm{H}_{2} \mathrm{O}_{2}$. Proteins $(100 \mu \mathrm{g})$ were oxidized by incubation $\left(3 \mathrm{~h}\right.$ at $\left.37^{\circ} \mathrm{C}\right)$ with differing concentrations of hydrogen peroxide $(1,5$, and $10 \mathrm{~mm})$ and were subsequently resolved by $2 \mathrm{DE}$ or SDS-PAGE; Cp profile was identified by WB. For the assessment of correlation between specific oxidative modifications (carbonylation) and Cp pI shift, CSF proteins were incubated $\left(5 \mathrm{~h}\right.$ at $\left.37^{\circ} \mathrm{C}\right)$ with 25 mM sodium ascorbate with or without $100 \mu \mathrm{M}$ ferrous chloride to induce protein carbonylation (as indicated by the OxyBlot kit manufacturer) (Musci et al., 1993). Carbonylation was analyzed by means of the OxyBlot Protein Oxidation Detection Kit (Millipore Bioscience Research 
Reagents) on the basis of carbonyl group derivatization with 2,4dinitrophenilhydrazine (DNPH).

Cp carbonylation was analyzed in two pools of CSF that were harvested from all $\mathrm{PD}$ patients and from all $\mathrm{CN}$ subjects, respectively. Equal amounts $(5 \mu \mathrm{g})$ of CSF proteins were taken from each patient to generate a total $70 \mu \mathrm{g}$ of proteins per pool. After derivatization with DNPH, proteins were resolved either by 2DE or by SDS-PAGE, and carbonyl groups were detected by Western blot with an anti-DNPH antibody, while $\mathrm{Cp}$ profiles were detected by means of an anti-Cp antibody on the same nitrocellulose membrane.

Bathophenanthroline assay. Cp ferroxidase activity was analyzed by bathophenanthroline (Btp) assay. Purified Cp (1.25 $\mu \mathrm{g})$ (Alexis) was incubated with $80 \mu \mathrm{M} \mathrm{FeSO}$ (ferrous form) and analyzed with a solution of $1 \mathrm{~mm}$ Btp in acetate buffer, pH 6.2, at five intervals $(0,15,30,45$, and $60 \mathrm{~min})$. Decrease in Btp-Fe ${ }^{2+}$ complex absorbance at $535 \mathrm{~nm}$ derives from ferrous iron oxidation into ferric form $\left(\mathrm{Fe}^{3+}\right)$. Cp ferroxidase activity was also analyzed after in vitro oxidation by hydrogen peroxide treatment, as described above $\left(1,5,10 \mathrm{mM} \mathrm{H}_{2} \mathrm{O}_{2}\right.$; $\mathrm{Cp}$ vs $\mathrm{H}_{2} \mathrm{O}_{2}$ molar ratio, $1 / 3000,1 / 15,000,1 / 30,000$, respectively), and after heat treatment $\left(99^{\circ} \mathrm{C}\right.$ for $30 \mathrm{~min}$ ). To identify the interference of copper released during protein oxidation/denaturation, we performed Btp assay without $\mathrm{Cp}$, but in the presence of $20 \mathrm{~nm} \mathrm{Cu}$.

Cell cultures and iron challenge. The human neuroblastoma SH-SY5Y (American Type Culture Collection) was cultured $\left(37^{\circ} \mathrm{C}\right.$ in a $5 \% \mathrm{CO}_{2}$ atmosphere) in a 1:1 mixture of Eagle's Minimum Essential Medium (ATCC) and F12 medium (ATCC) supplemented with 10\% fetal bovine serum.

Primary rat hippocampal neurons ( $\sim 80 \%$ purity) or pure astrocytes were prepared from 2- to 3-d-old Sprague Dawley rats, in respective accordance with Codazzi et al. (2006) and Bettegazzi et al. (2011). The Institutional Animal Care and Use Committee of the San Raffaele Scientific Institute approved the experimental procedures. Briefly, after subdivision of hippocampus matter into small sections, the tissue was incubated into Hanks solution that contained $3.5 \mathrm{mg} / \mathrm{ml}$ trypsin type IX (Sigma-Aldrich) and $0.5 \mathrm{mg} / \mathrm{ml}$ DNase type IV (Calbiochem). After mechanical dissociation, cells were plated onto poly-ornithine-coated coverslips and maintained in MEM supplemented with $5 \%$ fetal calf serum, B27 supplements (Invitrogen), and $3 \mu \mathrm{M}$ Ara-C (1- $\beta$-D-cytosinearabinofuranoside) (Sigma-Aldrich). Neuron cultures were maintained at $37^{\circ} \mathrm{C}$ in a $5 \% \mathrm{CO}_{2}$ humidified incubator and used as of $8-10 \mathrm{~d}$ from plating.

Pure astrocytes were grown in MEM supplemented with $10 \%$ horse serum. Two steps of overnight shaking at $230 \mathrm{rpm}$ were performed to induce selective detachment of microglia. Upon achievement of confluence, astrocytes were trypsinized and replated onto poly-lysine-coated plastic multiwells. Experiments were performed within $3 \mathrm{~d}$ of replating.

Protein expression was tested in cell lysates by WB as realized with anti-H-Ferritin (Ruggeri et al., 1992) (donated by Dr. S. Levi, Vita-Salute San Raffaele University, Milan, Italy) and with anti-Ferroportin (Fpn) (Abcam). To induce iron loading, cells were cultured for $20 \mathrm{~h}$ in a medium containing 10 and 5\% serum for the SH-SY5Y cell line and the primary culture, respectively. The medium was supplemented with ferric ammonium citrate (FAC) $(100 \mu \mathrm{M})$ and with ascorbic acid $(200 \mu \mathrm{M})$ to cause iron reduction and its internalization by DMT1 transporter. Extracellular iron and ascorbate (Asc) were subsequently removed, and the expression of ferroportin and ferritin were analyzed after further cell incubations (24 h), either with serum-free medium for SH-SY5Y or with low serum ( $1.25 \%$ derived from the presence of neuron culture conditioned medium) for primary neuron, in the absence of $\mathrm{Cp}$ (No Cp), or with functionally active purified $\mathrm{Cp}(5 \mu \mathrm{g} / \mathrm{ml})$, or with inactive oxidized $\mathrm{Cp}(\mathrm{Ox}-\mathrm{Cp})$. This latter was obtained by treatment with $5 \mathrm{~mm}$ hydrogen peroxide, as described above. Iron loading was also monitored through evaluation of ${ }^{55} \mathrm{Fe}$ retained in, and released by, the SH-SY5Y cells. SHSY5Y cells $\left(2 \times 10^{5}\right.$ cells/well, in triplicate) were iron loaded, as previously described, with FAC ( $95 \mu \mathrm{M})$ supplemented with $5 \mu \mathrm{M}{ }^{55} \mathrm{Fe}$-citrate (PerkinElmer) as a tracer. After $20 \mathrm{~h}$ incubation, the cells were washed, and one aliquot was kept for iron-loading evaluation and considered as $100 \%$, while other aliquots underwent further incubation $(24 \mathrm{~h})$ in 250 $\mu \mathrm{l}$ of serum-free medium containing $60 \mu \mathrm{M}$ apo-transferrin (SigmaAldrich), with or without extracellular ferroxidase activity, as previously described. After $24 \mathrm{~h}$ of incubation, media were collected, and cells were washed and lysed. Media $(50 \mu \mathrm{l})$ and cell lysates $(10 \mu \mathrm{l})$ were each mixed with $0.5 \mathrm{ml}$ of Ultima Gold (Packard) and counted $(3 \mathrm{~min})$ in a scintillation counter (Packard). Total protein content of cellular extracts was used to normalize radioactive counts both of lysates and of related media. Results were used to evaluate the differences in percentages of total iron contents.

To determine whether GPI-anchored membrane $\mathrm{Cp}$ as expressed by astrocytes was also susceptible to oxidation, we cultured pure rat astrocytes primary cultures either under resting conditions or upon treatment for $1 \mathrm{~h}$ with $0.6 \mathrm{mM} \mathrm{H}_{2} \mathrm{O}_{2}$. Cell lysates $(30 \mu \mathrm{g})$ were then analyzed by $2 \mathrm{DE}$ and $\mathrm{WB}$ to reveal the $\mathrm{Cp}$ electrophoretic pattern.

Densitometric analysis. Anti-Cp reactivity was quantified by laser densitometric analysis (GE Healthcare), as normalized by protein loading and total protein staining. The distribution of the $\mathrm{Cp}$ isoforms was evaluated by densitometric analysis of $2 \mathrm{D}$ spot optical density, which in turn was normalized as a percentage of total anti-Cp antibody reactivity. Signals obtained from OxyBlot were quantified by means of densitometric analysis and normalized by total protein loading. Ferritin expression was evaluated by densitometric analysis, and normalized by $\beta$-tubulin expression for SH-SY5Y cell line, and by $\beta$ III-tubulin expression for primary neuron.

Statistical analysis. Gender distribution was assessed by $2 \times 2$ contingency table analysis, which in turn used Fisher's exact test and two-tailed $p$ value. Continuous data (age distribution, CSF protein concentration, and spot/band volume) were evaluated by unpaired Student's $t$ test, if the data passed the normality test for Gaussian distribution as assessed by the Kolmogorov-Smirnov test, or were evaluated by Mann-Whitney test; two-tailed $p$ value was used for the comparison of two means and SE. Parametric one-way ANOVA was used to evaluate the statistical difference between three or more independent groups; postanalysis performed with Tukey's multiple-comparison tests was included. The receiver operating characteristic (ROC) curve was used to define the ability of the assay to discriminate between groups, and to define the threshold value at which optical density (OD) gave the best ratio between sensitivity and specificity. Correlation analysis was evaluated as Pearson's coefficient $(r)$. In all analyses, $p<0.05$ was considered to be statistically significant. The analysis was performed with Prism, version 4.03, software (GraphPad).

Image processing and unsupervised machine learning techniques for 2DE-Western blot image analysis. Denoising was executed by nonlinear spatial adaptive image filtering, and background removal was obtained by 3D-morphological operators (Cannistraci et al., 2009). After preprocessing, each 2DE-WB image was aligned by raw vectorization of its pixel intensity; each pixel intensity accordingly became a feature in a vector that characterized the Cp image sample. To implement the subsequent machine learning analysis, features (pixels) with small profile variance were filtered out to reduce the number of low informative features (Kohane et al., 2003). Classification of Cp profiles was provided by the combined application of (1) unsupervised machine learning approaches designed to reduce linear dimensionality and executed by principal component analysis, and of (2) minimum curvilinear affinity propagation (MCAP) as a method for clustering analysis (Cannistraci et al., 2010). Said tool was applied to the two-dimensional projection space obtained as the outcome of dimensionality reduction.

\section{Results}

\section{Ceruloplasmin shows differing isoform patterns in $\mathrm{PD}$}

Cp expression was analyzed by SDS-PAGE and WB on CSF proteins. Immunoblots indicated that, once normalized for total proteins, the PD Cp expression level did not vary from that of control subjects $(\mathrm{CN})$ (data not shown) and thus confirmed data already reported (Loeffler et al., 1994). As examined under 2DE, CSF Cp showed several isoforms with distinct isoelectric points $(\mathrm{pI})$ and a relative molecular mass of $\approx 150 \mathrm{kDa}$; the distribution of said points differed between PD and CN (Fig. $1 A$ ). To analyze $\mathrm{Cp}$ patterns, we used a constant $\mathrm{pI}$ threshold ( $\mathrm{pH}$ 5.6) to divide 
A

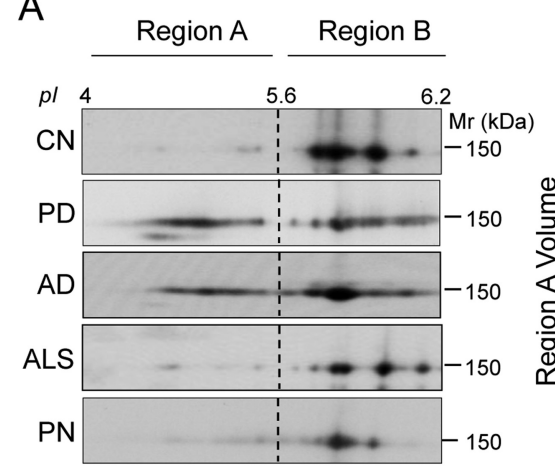

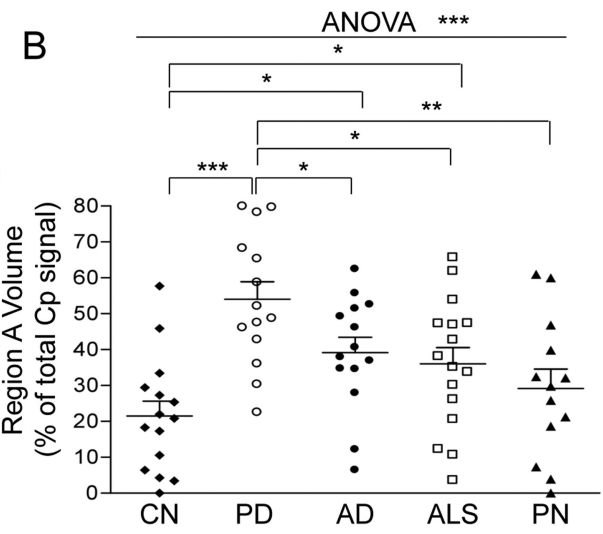
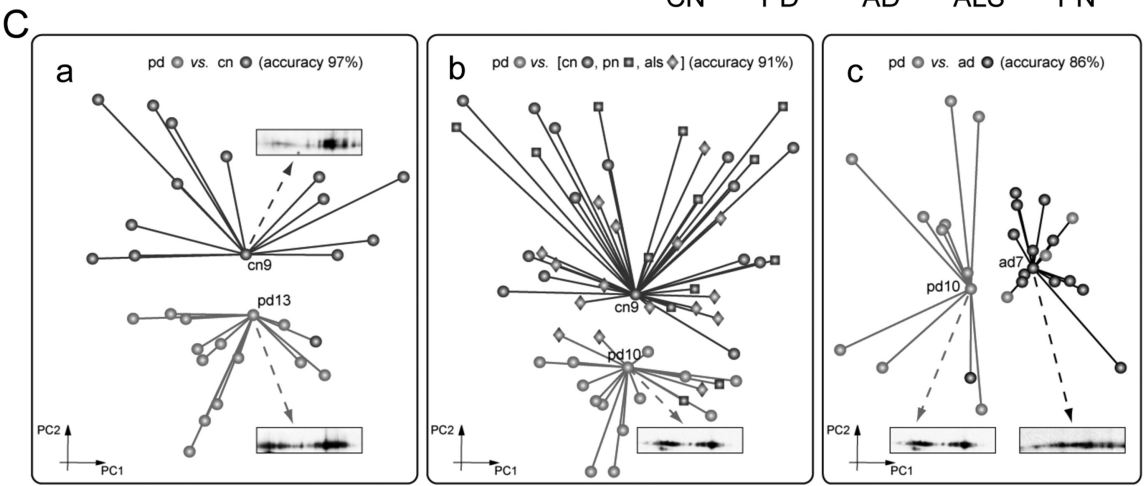

Figure 1. CSF Cp 2DE profile discriminates PD from $A D, A L S, P N$, and CN. $A$, Representative results for WB analysis performed with anti-Cp on 2DE-resolved proteins. On the basis of pl threshold value, Cp signal distribution was divided into two distinct areas, regions $A$ and $B$. $B$, Analysis of WB signal optical density value distribution in region $A$, evaluated as a percentage of the total $C p$ signal. Data were analyzed both by Student's $t$ test and by ANOVA. Single patient distributions as well as means and SE are shown $(\mathrm{PD}, n=14 ; \mathrm{CN}, n=15 ; \mathrm{AD}, n=14 ; \mathrm{ALS}, n=16 ; \mathrm{PN}, n=13)\left({ }^{*} p<0.05 ;{ }^{* *} p<0.005 ;{ }^{* * *} p<0.001\right)$. C, Unsupervised cluster identification discriminates $(p$ pattern of $P D$ patients from other groups. Dimensionality reduction of the anti-Cp WB images data set executed by principal component analysis (the first two principal components, $P C 1$ and $P(2$, are shown), and clusters of homogeneous subjects were identified by unsupervised minimum curvilinear affinity propagation clustering analysis. Light gray clusters are for PD attribution, and dark gray and black clusters for non-PD attribution. Markers associated with sample names indicate the exemplars for the respective cluster. An original 2DE-WB image is displayed for each exemplar. $\boldsymbol{a}$, Clustering of PD and CN. Sample $\mathrm{cn} 13$ proved to be misclassified. $\boldsymbol{b}$, Clustering of PD, CN, PN, and ALS subjects. Five of 58 samples were misclassified, from left to right, als7, als5, pn4, als10, pn6. c, Clustering of PD and AD patients. Four of 28 samples proved to be misclassified (from left to right, ad8, pd13, pd14, pd11).

the profile into two distinct areas: region A and region B (Fig. $1 A)$. Analysis of the respective distribution of the signal to the two regions, each distribution being evaluated as a percentage of the total Cp signal, showed significantly higher values $(t$ test, $p<$ 0.0001 ) in the acidic region A for PD than for CN patients (Fig. $1 B)$. This represents the fraction of total $\mathrm{Cp}$ that is modified in the CSF of PD patients. The distribution of Cp signal in the two regions was investigated by means of ROC curve analysis, which showed a PD versus $\mathrm{CN}$ area under the curve of $0.919(p=$ 0.00012 ) (Fig. 2A). Application of a signal cutoff value in region A $>46.02 \%$ enabled discrimination of $\mathrm{PD}$ from $\mathrm{CN}$ patients with a sensitivity of $71.4 \%$ and a specificity of $93.3 \%$ (likelihood ratio, 10.7). Interestingly, PD patients' clinical status (as UPDRS score, Table 1) and $\mathrm{Cp}$ acidification (signal in region $\mathrm{A}$ as percentage of total WB Cp signal) were found to correlate (Pearson's correlation coefficient $r=0.745 ; p=0.0022$ ) (Fig. $2 B$ ).

To understand whether $\mathrm{Cp}$ isoform acidification is a feature shared by other neurological pathologies, we analyzed the $\mathrm{Cp}$ pattern in CSF from patients affected by AD, ALS, and PN. Cp signal distribution enabled us to discriminate $\mathrm{PD}$ from the other neurological pathologies ( $t$ test: $\mathrm{PD}$ vs $\mathrm{AD}, p=0.0310$; $\mathrm{PD}$ vs ALS, $p=0.0119$; PD vs PN, $p=0.0022$ ) (Fig. $1 A, B$ ). The analysis also showed a difference between $\mathrm{CN}$ and, respectively, $\mathrm{AD}(p=$
$0.0060)$ and ALS $(p=0.0253)$, while no differences between $\mathrm{CN}$ and $\mathrm{PN}$ were observed ( $p>0.05$ ) (Fig. $1 A, B$ ). A statistically significant result was obtained even when the five independent groups were evaluated together by ANOVA test ( $p=$ $0.0001)$. Postanalysis test was significant for PD versus $\mathrm{CN}(p<0.001)$ and $\mathrm{PD}$ versus PN $(p<0.01)$ comparisons (Fig. $1 B)$. Collectively, these results suggest that the Cp present in PD CSF is affected by modifications that induce protein acidification, which in turn is underlined by signal accumulation in the acidic region $\mathrm{A}$.

\section{Unsupervised analysis uncovers a discriminative pattern for $\mathrm{Cp}$ in PD patients}

We applied a fully unsupervised automatic computational classification methods; by means of unsupervised machine learning applied to the image pixels, this classification offers dimensionality reduction, feature selection, and clustering of the 2DE anti-Cp WB map data set. Dimensionality reduction allowed the display of images in a new two-dimensional projection space, within which cluster analysis identified two groups, one corresponding to $\mathrm{CN}$ and the other to PD (Fig. $1 \mathrm{Ca}$, dark gray and light gray clusters, respectively). This identification confirms that $\mathrm{Cp}$ pattern is able to distinguish $\mathrm{PD}$ from CN (accuracy, 96\%), with the single exception of CN13. Moreover, MCAP clustering revealed two respectively representative exemplars (CN9 and PD13) for the given clusters (Fig. $1 \mathrm{Ca}$ ). The WB map for the cluster exemplars provides an explanatory comparison between prototypes of the two states (Fig. $1 \mathrm{Ca}$ ). Similarly, $\mathrm{Cp}$ pattern is able to distinguish the PD cluster from the cluster comprised of those CN, PN, and ALS subjects who proved to be homogeneous (Fig. 1Cb); accuracy was $91 \%$, with 5 of 58 subjects misclassified (ALS5, -7, -10, and PN4, -6). When analyzed together with other groups, $\mathrm{AD}$ patients failed to be homogeneously distributed in a single cluster and thus obstructed unsupervised analysis (data not shown). Interestingly, when directly compared, $\mathrm{AD}$ and $\mathrm{PD}$ groups were $86 \%$ accurately recognized by unsupervised $\mathrm{Cp}$ pattern analysis (Fig. 1Cc) (4 of 28 subjects misclassified; AD8 and PD11, $-13,-14)$. Comparison of the WB maps corresponding to the cluster exemplars (Fig. $1 C c$, PD10 and AD17) shows that, of the two prototypal states, AD Cp undergoes lesser modification.

\section{In vitro oxidative stress induces $\mathrm{Cp}$ interconversion to acidic} isoforms and an increase in CSF total protein carbonylation It has been shown that, because of its interaction with metal cofactors, Cp is sensitive to oxidative stress (Kang et al., 2001). We accordingly hypothesized that the oxidative stress affecting CNS in PD patients might induce sufficient protein modifications to change $\mathrm{pI}$. Given the hypothesis that $\mathrm{Cp}$ is a protein with a 5.5 d half-life (Hellman and Gitlin, 2002), chronic exposure 

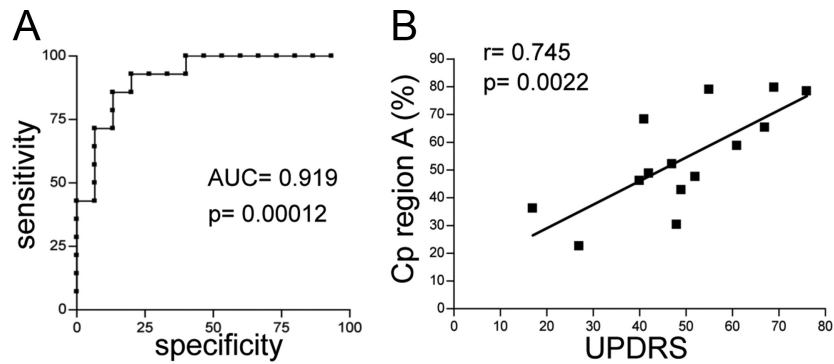

Figure 2. Cp pattern acidification discriminates healthy subjects and correlates with Parkinson's disease grading. $A$, The ROC curve was used to define the ability of the assay to discriminate between PD and CN groups, and to define the threshold value at which OD gave the best ratio between sensitivity and specificity. PD versus $\mathrm{CN}$ showed an area under the curve (AUC) of 0.919 with $p=0.00012$. A signal cutoff value in region $A>46.02 \%$ enabled discrimination of PD from CN patients with a sensitivity of $71.4 \%$ and a specificity of $93.3 \%$. B. Correlation analysis was evaluated as Pearson's coefficient $(r$ ) between ( $p$ signal in region $A$ (as a percentage of total WB (p signal) and PD clinical status (as UPDRS score) for each patient. UPDRS and (p signal in region A values passed the normality test for Gaussian distribution as assessed by KolmogorovSmirnov test. Correlation showed a coefficient $r=0.745$ with $p=0.0022$.
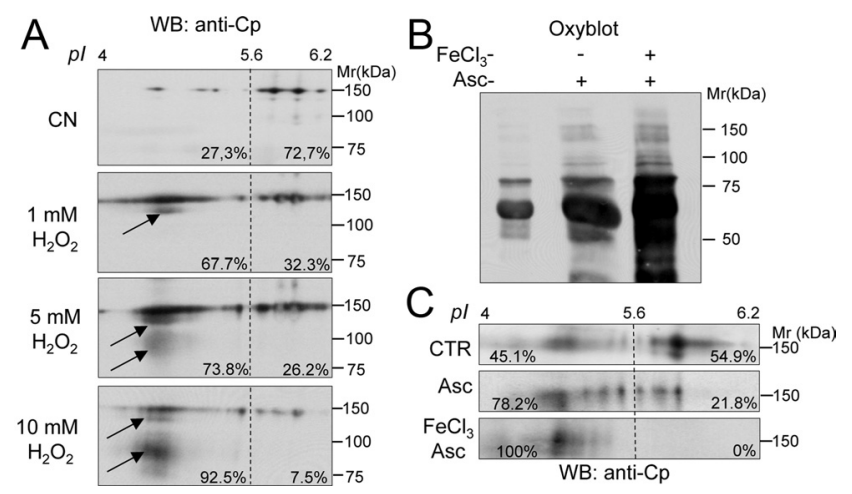

Figure 3. In vitro oxidative stress induces $\mathrm{Cp}$ to convert to acidic isoforms and total CSF protein carbonylation to increase. $A$, WB analysis of Cp profile in the CSF from a representative $\mathrm{CN}$ subject resolved by 2DE under resting conditions or after treatment with increasing amounts of $\mathrm{H}_{2} \mathrm{O}_{2}(1,5,10 \mathrm{~mm})$; percentages indicate the amount of total $\mathrm{Cp}$ signal present in regions $\mathrm{A}$ and $B$ (Fig. 1); the arrows indicate low-molecular-weight products generated by protein oxidation. $\boldsymbol{B}$, Detection of protein carbonylation by 0xyBlot assay on total CSF proteins resolved by SDS-PAGE and stained for carbonyl groups, under resting conditions or after oxidation obtained by treatment with Asc with or without ferrous chloride $\left(\mathrm{FeCl}_{3}\right) . \mathrm{C}, \mathrm{WB}$ analysis of $2 \mathrm{DE}$ Cp profile in the CSF under resting conditions or after oxidation treatments as in $\boldsymbol{B}$; percentages indicate total C $p$ signal present in regions A and B (Fig. 1).

even to mild oxidative conditions may result in extensive oxidative modifications. To confirm this hypothesis, we induced in vitro oxidative stress on CN CSF, and we analyzed the resulting Cp pattern. It is known that, in in vivo experiments, an increase in $\mathrm{H}_{2} \mathrm{O}_{2}$ concentration correlates with an increase in ROS concentration (Cozzi et al., 2010); we accordingly used a high $\mathrm{H}_{2} \mathrm{O}_{2}$ concentration treatment to mimic the prolonged exposure of the $\mathrm{Cp}$ to an oxidative environment. We observed that increased $\mathrm{H}_{2} \mathrm{O}_{2}$ concentration led to proportional shifts in Cp isoforms to the acid region (Fig. $3 A$ ). Oxidation also induced the progressive generation of two Cp products, amounting to $\sim 120$ and $80-100$ $\mathrm{kDa}$, respectively (Fig. $3 A$, indicated by arrows). These products were probably degradation fragments, as previously reported (Choi et al., 2000). Interestingly, the $120 \mathrm{kDa}$ product was detectable in most (10 out 14) PD patients (Fig. 1A). The CSF Cp pattern obtained by oxidative treatment was similar to that observed in PD patients, a finding that suggests that changes might be due to oxidative modifications.
Among several modifications induced by oxidative stress, one of the most common is protein carbonylation (Dalle-Donne et al., 2003), and we accordingly analyzed this modification in CSF. Metal-catalyzed oxidation induced by treatments with high concentration of ascorbate, both with and without $\mathrm{FeCl}_{3}$, produced mild and strong carbonylation, respectively [see OxyBlot assay manufacturer indications and the study by Musci et al. (1993)], and resulted in a proportional increase in OxyBlot reactivity (Fig. $3 B)$. Subsequently to these treatments, the $\mathrm{Cp} 2 \mathrm{DE}$ pattern showed a shift to region $\mathrm{A}$ that was proportional to the degree of carbonylation (Fig. $3 B, C$ ). Albeit at different levels, these changes were similar to those obtained with $\mathrm{H}_{2} \mathrm{O}_{2}$ treatment (Fig. $3 \mathrm{~A}, \mathrm{C}$ ) and hence suggest that protein oxidation contributes to $\mathrm{Cp}$ isoform changes.

\section{CSF total protein carbonylation increase in PD patients}

Analysis of total protein carbonylation in the CSF obtained from PD patients showed a significantly greater level than that of control subjects ( $p=0.0015)$ (Fig. $4 A-C)$. This suggests that CSF proteins undergo oxidative modifications during the course of PD pathological events. However, in contrast with Cp 2DE shift, no correlations were observed between severity of disease and CSF total protein carbonylation levels. This finding is plausible, given the diversity of the parameters that we tracked: on the one hand, electrophoretic mobility changes in single/individual $\mathrm{Cp}$ proteins, as possibly induced by several, differing forms of modification; on the other hand, specific changes in carbonylation levels as evaluated in total CSF proteins as a collective whole.

\section{Cp carbonylation occurs in PD patients, and modified Cp corresponds to acidic isoforms}

OxyBlot analysis, performed on 2DE-resolved CSF proteins from both the pool of PD patients and the pool of $\mathrm{CN}$ subjects, followed by staining on the same nitrocellulose for Cp expression, showed that the Cp present in PD CSF was carbonylated (Fig. $4 D)$. Moreover, the carbonylation signal was found to correspond mainly with more acidic $\mathrm{Cp}$ isoform, a feature that did not appear in the $\mathrm{CN}$ subjects (Fig. $4 D$, see arrows). This analysis was restricted to the pooled samples due to the limited amount of samples available. However, the same analysis performed on a single PD patient (PD2), from whom we had by chance collected a larger amount of CSF, showed the same results (Fig. 4E). Carbonylation converts side chains of many amino acids to reactive aldehyde and ketone groups, and thus may causes loss of positive charges, which in turn results in protein acidification. For this reason, it is conceivable that oxidative stress-induced $\mathrm{Cp}$ carbonylation might contribute to the isoform switch observed both in vitro and in $\mathrm{PD}$ patients.

However, the complexity of the Cp 2DE pattern observed indicates that the oxidation-induced changes involved multiple target sites and varying events (e.g., methionine and cysteine oxidation, asparagine deamidation, glucidic moiety modifications, etc.). In particular, the shift to acidic pI values may have resulted from the formation of sulfinic acid on some of the 15 cysteine residues present in $\mathrm{Cp}$. These alterations are now under investigation. Moreover, the oxidative modifications that triggered $\mathrm{Cp}$ acidification in PD patients were irreversible, since neither antioxidant (200 $\mu \mathrm{M}$ ascorbate) nor catalase treatment reverted the isoform switch (data not shown).

\section{Oxidation decreases $\mathrm{Cp}$ ferroxidase activity}

The literature reports a reduced level of ferroxidase activity in PD CSF (Boll et al., 1999, 2008), and it is noteworthy that CSF fer- 

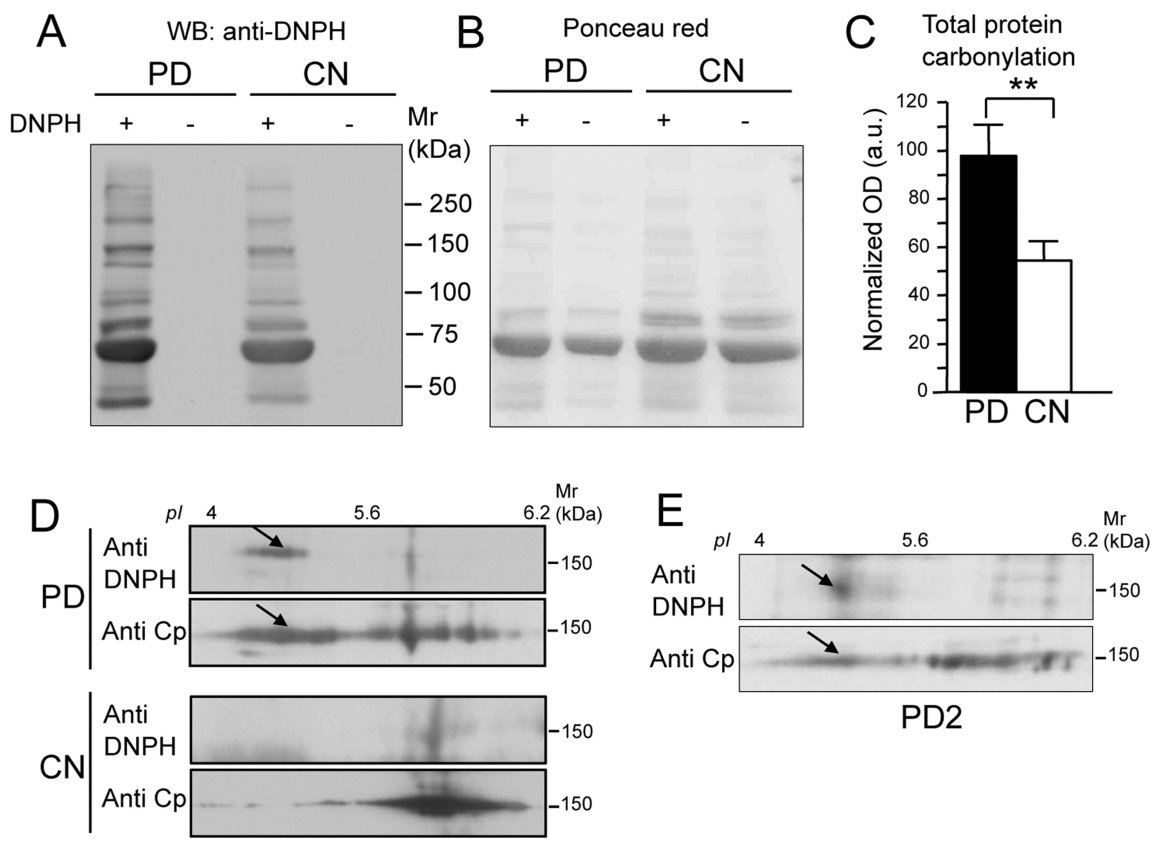

Figure 4. CSF total protein carbonylation is increased in PD patients and Cp is a carbonylation target. $A$, Representative gel of OxyBlot assay for carbonyl group detection. CSF total proteins from PD patients and healthy subjects $(\mathrm{CN})$ were resolved by SDS-PAGE either after derivatization with DNPH $(+)$ or without derivatization $(-)$, and analyzed by WB with anti-DNPH for carbonylation detection. $\boldsymbol{B}$, Ponceau red staining of the nitrocellulose used for $0 x y$ Blot assay shows that proteins were loaded in equal amounts. $C$, Evaluation of total protein carbonylation detected in the CSF of PD patients $(n=14)$ and CN subjects $(n=15)$ : the $y$-axis indicates $0 x y B l o t$ signal $O D$ values (in arbitrary units) normalized by total protein loading. Data were analyzed by Student's $t$ test; means with SE are indicated ( $\left.{ }^{* *} p<0.005\right)$. D, CSF proteins from both the PD patient pool and the CN subject pool were resolved by $2 \mathrm{DE}$ after derivatization with DNPH. Carbonylation was revealed with anti-DNPH antibody, and the same nitrocellulose membrane was further stained with anti-Cp to detect signal colocalization. $\boldsymbol{E}$, The same analysis as in $\boldsymbol{D}$, performed on a single PD patient (PD2), from whom greater amounts of CSF had by chance been collected showed identical results. The arrows indicate the colocalization of carbonylated spots with C $p$ acidic spots.
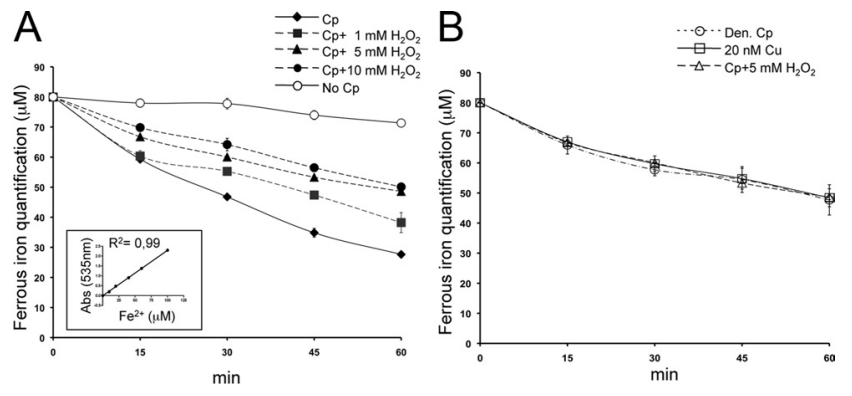

Figure 5. Oxidation decreases $(\mathrm{C}$ ferroxidase activity. $A$, Ferroxidase activity was analyzed by Btp assay. Purified $\mathrm{Cp}(1.25 \mu \mathrm{g})$ was incubated with $60 \mu \mathrm{M} \mathrm{FeCl}$ (ferrous form) and analyzed at five different times $(0,15,30,45,60 \mathrm{~min})$ with a solution of $1 \mathrm{~mm}$ Btp. The decrease in absorbance at $535 \mathrm{~nm}$ of Btp-Fe ${ }^{2+}$ complex is due to ferrous iron oxidation into ferric form $\left(\mathrm{Fe}^{3+}\right)$. Ferroxidase activity was also analyzed after oxidation by $\mathrm{H}_{2} \mathrm{O}_{2}$ treatments $(1,5,10 \mathrm{~mm})$. By way of control, the assay was performed in the presence of buffer alone (№ Cp). Means with $\mathrm{SE}$ are indicated $(n=5)$. The inset shows linear regression of the Btp-Fe ${ }^{2+}$ complex optical density at $535 \mathrm{~nm}$ with different $\mathrm{Fe}^{2+}$ micromolar concentrations. $\boldsymbol{B}$, Btp assay performed with C $p$ after $50 \mathrm{~mm} \mathrm{H}_{2} \mathrm{O}_{2}$ treatments, with heat-denatured $\mathrm{Cp}$ (Den Cp), and with buffer alone containing $20 \mathrm{~nm} \mathrm{Cu}^{2+}$, the concentration reached by the Cu released from $1.25 \mu \mathrm{g}$ of denatured Cp.

roxidase activity mainly corresponds to Cp activity (Vassiliev et al., 2005; Madsen and Gitlin, 2007). To investigate the connection between oxidative modifications and $\mathrm{Cp}$ function, we analyzed the ferroxidase activity of purified $\mathrm{Cp}$. We observed that a reduction in ferroxidase activity correlated with increases in $\mathrm{H}_{2} \mathrm{O}_{2}$ concentrations (Fig. 5A). Apparently, ferroxidase activity inhibition was not complete (Fig. $5 A$ ), as a result of the interfer- ence of the copper $(\mathrm{Cu})$ atoms released by $\mathrm{Cp}$ during denaturation by oxidative treatment with the Btp assay (Baraj et al., 1998). As already reported, Cp heat denaturation leads to $\mathrm{Cu}$ release (Kang et al., 2001), and under this condition we obtained ferroxidase activity profiles that closely resemble those obtained with strong protein oxidation (Fig. 5B). A similar decrease in iron detection was observed in an assay that used a mere $20 \mathrm{~nm}$ $\mathrm{Cu}$, a concentration that equates to the $\mathrm{Cu}$ concentration releasable after denaturation of the total amount of $\mathrm{Cp}$ used in our assay (Fig. 5B). These results indicate that $\mathrm{Cp}$ oxidation impairs ferroxidase activity; as reported (Musci et al., 1993), this impairment induces structural changes that lead in turn to the release of Cpcoordinated $\mathrm{Cu}$ atoms, which are necessary for enzymatic activity.

\section{Extracellular oxidized $\mathrm{Cp}$ favors intracellular iron accumulation}

Impairment of the extracellular ferroxidase activity of GPI-bound membrane Cp has been reported to block iron efflux from cells by downmodulation of Fpn, a membrane ferrous iron transporter (Jeong and David, 2003; De Domenico et al., 2007), with the ensuing increase of intracellular iron accumulation. We investigated whether similar iron retention might be induced by nonfunctional soluble Cp in dopamine hydroxylase-positive cells that do not express membrane GPI-Cp. The SH-SY5Y neuroblastoma cell line was iron loaded by treatment with FAC and with Asc in the presence of serum, and duly demonstrated the upregulation of the Fe storage protein ferritin (Fig. 6A,B); extracellular iron was subsequently removed, and cells were further incubated in the medium alone (without serum), or in the presence either of functional Cp, or of oxidized $\mathrm{Cp}$. In the presence of functional $\mathrm{Cp}$, we observed a decrease of ferritin expression (Fig. 6A,B), which, in turn, indicates functional $\mathrm{Fe}^{2+}$ exportation from cells. In contrast, the absence of extracellular ferroxidase activity (absence of $\mathrm{Cp}$ or presence of Ox-Cp) witnessed high ferritin levels ( $p=0.0040$ and $p=0.0173$, respectively), which suggests a impairment in iron efflux from cells (Fig. 6A,B). A similar conclusion was inferred from the direct evaluation of the radioactive Fe released into the medium or retained in the cells. Both in the absence of $\mathrm{Cp}$ and in the presence of $\mathrm{Ox}-\mathrm{Cp}$, cells showed, in comparison with functional Cp, a $13-23 \%$ increase in iron retention (Fig. $6 C$ ), and a corresponding reduction in $\mathrm{Fe}^{2+}$ export that ranged from 26.5 to 46.9\% (Fig. 6D) (Cp vs No Cp, $p=0.0325$; Cp vs Ox-Cp, $p=$ 0.0112 ; Student's $t$ test). The reduced iron efflux was not paralleled by a statistically significant downmodulation in Fpn expression level as assessed by WB, even though a trend of expression decrease was observed in the absence of extracellular ferroxidase activity (Fig. $6 A$, No Cp and Ox-Cp).

To evaluate whether $\mathrm{Cp}$ contribution to pathological mechanism is effective in primary cells, which proved to be more sensitive to intracellular iron accumulation than did the cell line model (Pelizzoni et al., 2011), we also tested Cp functionality on 
iron homeostasis in rat primary neuronal culture. This culture produced ferritin expression results that resemble those acquired with the dopaminergic cell line, a finding that in turn implies intracellular iron retention.

The iron load, induced by treatment with FAC and Asc, promoted an upregulation of ferritin (Fig. $7 A, B$ ). After iron removal, the neurons were maintained for $24 \mathrm{~h}$ in medium with low serum $(1.25 \%$ derived from the presence of neuron culture conditioned medium) in the absence (No $\mathrm{Cp}$ ) or in the presence of functional $(\mathrm{Cp})$ or oxidized (Ox-Cp) ceruloplasmin. A significant reduction of ferritin expression was observed only in the presence of extracellular functional Cp $(p=0.0303$, Mann-Whitney test), while neither Ox-Cp nor No-Cp conditions were able to promote iron export (Fig. $7 A, B$ ). The decrease in ferritin expression in the presence of extracellular functional $\mathrm{Cp}$ was significant compared with neuron invariability observed in the presence of $\mathrm{Ox}-\mathrm{Cp}$ ( $p=0.0041$, Mann-Whitney test) (Fig. $7 A, B)$. The high variability observed with primary culture in multiple experiments $(n=5)$ might be due to the residual ferroxidase activity in the serum.

Similar results, albeit with lower differences, were obtained when primary cultures after FAC loading were kept only $6 \mathrm{~h}$ under treatment conditions in the presence of low serum to exclude a putative role of neuronal suffering during the treatment (data not shown). We ruled out the hypothesis that astrocyteexpressed GPI-Cp plays a role in the cocultures because astrocyte levels in the cultures were very low, as evaluated by anti-GFPA/ anti- $\beta$ III-tubulin reactivity ratio (range, $0.013-0.011$ ). This estimation excludes also a contribution of astrocytes in the ferritin signal obtained in hippocampal cultures. Moreover, in pure hippocampal astrocyte cultures, subjected to the same treatments, the ferritin levels and variations were almost undetectable (data not shown).

Since GPI-anchored Cp as expressed by astrocytes plays a major role in brain iron homeostasis, we investigated whether this $\mathrm{Cp}$ isoform might also be the target of pathological oxidative conditions. Pure primary rat astrocytes exposed to oxidative conditions compatible with cell survival $\left(0.6 \mathrm{~mm} \mathrm{H}_{2} \mathrm{O}_{2}\right)$ showed that the GPI-Cp 2DE pattern profile [which differs from its soluble Cp equivalent (Conti et al., 2008)] had shifted to a more acidic $\mathrm{pH}$ (Fig. 7C). This finding indicates that astrocyte-expressed membrane GPI-Cp undergoes oxidative modifications too.

\section{Discussion}

The analysis of CSF has implications in the diagnosis of neurological diseases because it contains proteins that derive from brain metabolism. Likewise, the identification of proteins sensitive to oxidative stress might contribute to the characterization of CNS damage in neurodegenerative diseases. Our results suggest that changes in Cp electrophoretic pattern might be considered as a potential marker for the evaluation of oxidative stress levels in the CNS of PD patients; our suggestion derives from the link between $\mathrm{pI}$ modification of Cp isoforms and CSF oxidation. In particular, at symptomatology onset (i.e., the collection time
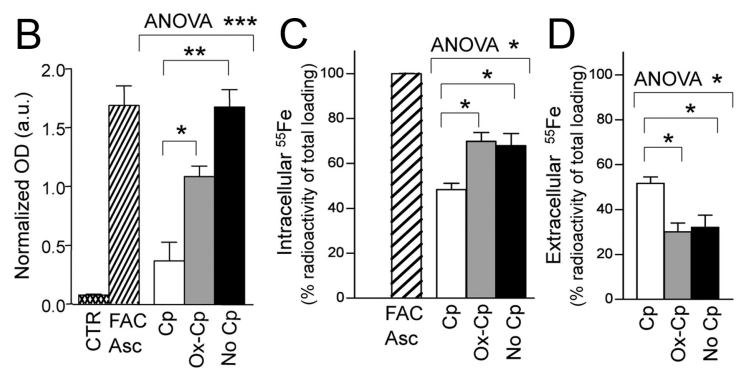

Figure 6. Extracellular oxidized (p favors intracellular iron accumulation. A, SH-SY5Y neuroblastoma cells maintained in medium supplemented with $10 \% \mathrm{FBS}$ (CTR) were iron loaded by treatment $(20 \mathrm{~h})$ with FAC (100 $\mu \mathrm{m})$ and Asc (200 $\mu \mathrm{m})$. Extracellular as a tracer. After $20 \mathrm{~h}$ incubation, the cells were washed, and one aliquot ( $2 \times 10^{5}$ cells/well, in triplicate) was kept for (in triplicate for each condition) were normalized on the basis of total protein contents and used to after $24 \mathrm{~h}$ incubation in serum-free medium alone (No $(p)$, or in the presence either of functional $C p$ or of inactive oxidized $C p$ were used for the calculation of percentages of iron released from total intracellular iron loading. Data in $\boldsymbol{B}-\boldsymbol{D}$ were analyzed by both unpaired ANOVA and Student's $t$ test; respective means with SE of five $(\boldsymbol{B})$ and three $(\boldsymbol{C}, \boldsymbol{D})$ independent experiments are

used for all samples in the current study), Cp oxidative modifications seem to be relevant to those neurological diseases in which damage is mostly confined to the brain. In fact, analysis of CSF obtained from $\mathrm{AD}$ patients has shown Cp modifications that are similar to, but distinguishable from, those observed in PD patients. In contrast, ALS patients, in whom spinal motor neurons are involved, have not shown substantial Cp modifications. Alternatively, it might be that neurodegenerative diseases differ in the lead times they respectively need before CNS oxidative damage becomes substantial. The analysis of CSF Cp oxidation during the progression of neurological disease could reveal a link between gradual CNS oxidative damage and specific pathological symptoms. Of note is the correlation that we observed between the PD rating and the amount of oxidized Cp. The identification of representative pathological clusters by unsupervised pattern recognition procedures confirms the potential role of $\mathrm{Cp}$ analysis for clinical applications. Cp analysis in $\mathrm{PD}$ patients under treatment, for example, might be used to monitor therapy efficacy by disclosing the prooxidative side effects of chronic L-Dopa administration (Muller et al., 2004), and by modulating the iron chelator or antioxidant compound treatments.

In vitro CSF oxidation induced $\mathrm{Cp}$ modifications that were similar to those observed in patients. Moreover, CSF analysis in PD patients confirmed that carbonylation of total proteins increases and that this modification affects Cp contributing, together with varying additional oxidative modifications, to its acidification. This suggested the presence, in the CSF of PD, of some oxidative agents able to modify the proteins. Although CSF protein carbonylation level has already been proposed as a marker for oxidative damage (Dalle-Donne et al., 2003), the evaluation of Cp electrophoretic pattern seems to be the most sensitive technique for oxidative status analysis, probably due to the presence of six $\mathrm{Cu}$ ions in the molecule (Kang et al., 2001). The observed correlation between CSF Cp oxidation and the UPDSR grading of PD patients lends weight to the importance of our approach for clinical diagnosis. Previous studies suggested a cor- 
A

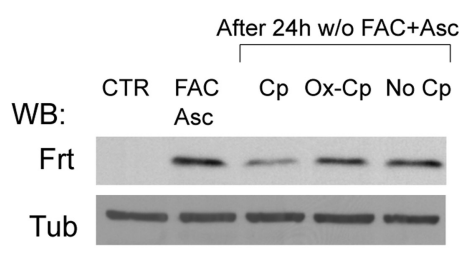

B

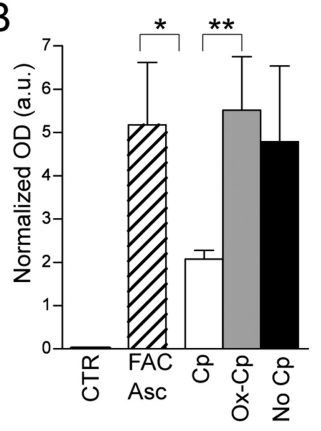

C

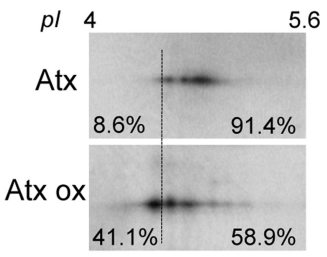

1993), these effects derived from oxidative modifications that induce Cp conformational changes. Thus, the changes observed in CSF $C p$ from $P D$ and $A D$ patients might reflect accelerated protein aging, as induced by oxidative pathological conditions (Grimm et al., 2011).

Iron metabolism impairment is the major consequence of the loss of Cp activity. Indeed, both aceruloplasminemia patients and the Cp-deficient mice are characterized by an increase in intracellular iron that correlates with motor dysfunction (Harris et al., 1998; Patel et al., 2002); a critical role for Cp ferroxidase activity in iron metabolism has also been indicated in Wilson's disease (Merle et al., 2010). Cp ferroxidase activity is essential for iron metabolism because it regulates the expression of Fpn iron transporter on cell membranes (De Domenico et al., 2007). Intracellular iron concentration is controlled both by the storage protein ferritin, which accumulates $\mathrm{Fe}^{3+}$, and by

relation of low serum Cp expression with the development of PD (Bharucha et al., 2008) and with nigral iron deposition (Jin et al., 2011). In contrast, other studies have concluded that $\mathrm{Cp}$ levels are not of diagnostic value (Loeffler et al., 1994; Tórsdóttir et al., 2006). However, these studies evaluated Cp merely as an expression level in sera. We have not found alterations in Cp profile in the sera of PD patients (data not shown). The novelty of our results, therefore, is that they introduce $\mathrm{Cp}$ isoform patterns in $\mathrm{CSF}$ as a way to discriminate between patients. We are aware that the relatively small size of our cohort is a limitation, one that derives from the fact that the enrolment of PD patients in the protocols is voluntary, since, in contrast with what applies for ALS, AD, and PN, CSF analysis is not a diagnostic procedure for PD. Nonetheless, our results are promising and will facilitate the approval of further enlarged studies.

The link we show between Cp oxidation and PD might be a side effect of the real cause of neurodegeneration. Alternatively, as indicated by the intracellular iron accumulation, said link might play a role in pathological mechanisms. In PD, imbalances between the generation of oxidant products and ROS scavenging systems, together with improper iron metabolism, contribute to neurological damage (Youdim et al., 2004). Reduced CSF ferroxidase activity (Boll et al., 1999, 2008), increased oxidative stress in CNS, and iron overload in SN (Götz et al., 2004) are PD features that potentially connect to the Cp oxidation here observed. The functionality reduction that follows $\mathrm{Cp}$ oxidation correlates with a Cp electrophoretic pattern similar to that observed in CSF of PD. Given that CSF ferroxidase activity is substantially due to Cp (Madsen and Gitlin, 2007), it is reasonable to associate the Cp oxidative modifications found in PD patients with the reported reduction in CSF ferroxidase activity (Boll et al., 1999, 2008). Furthermore, oxidative modification in Cp leads to copper release (Kang et al., 2001; this study), a finding that possibly explains why copper increases in the CSF of both $\mathrm{PD}$ and $\mathrm{AD}$ patients (Boll et al., 2008; Brewer et al., 2010). Copper ions released from oxidized $\mathrm{Cp}$ facilitate Fenton's reaction, which amplifies general protein damage (Kang et al., 2002). Similar pI shifts and increases in carbonyl contents to those we here describe have been reported for serum Cp during aging (Musci et al.,
$\mathrm{Fe}^{2+}$ efflux through Fpn accompanied by Cp extracellular ferroxidase activity (Madsen and Gitlin, 2007). In our experimental model, the absence of extracellular ferroxidase activity as a result of Cp oxidation leads to cellular iron retention both in SH-SY5Y cell line and, even more important, in primary neuronal culture. In fact, the primary neurons are more susceptible to intracellular iron accumulation than the cell line counterpart (Pelizzoni et al., 2011), a feature that better reflects what occurs in vivo under pathological conditions. The weak Fpn downmodulation and the lack of a complete intracellular iron retention that we observed suggested the presence of compensatory mechanisms. One of these may consist in the described role of the $\beta$-amyloid protein precursor (APP). Like Cp, APP is expressed in transmembrane and secreted forms, and has been reported to exert ferroxidase activity that in turn promotes neuronal iron export through the Fpn (Duce et al., 2010). The inhibition of APP-ferroxidase activity results in neuronal iron accumulation; this finding suggests that various molecules in varying tissues and pathologies may share a common mechanism of neuronal damage. It has been proposed that $60 \%$ of brain ferroxidase activity derives from the membrane GPI-Cp isoform, which is expressed by astrocytes, and $40 \%$ from APP, which is expressed by neurons (Duce et al., 2010). However, account must also be taken of the ferroxidase activity exerted by the soluble forms of Cp and APP contained in CSF, which permeates the brain (Moos et al., 2007).

Alternatively, the iron retention we detected in the absence of extracellular ferroxidase activity might be generated by an impairment in Fpn functionality rather then by membrane downmodulation. This explanation is supported by data reporting that Fpn expression does not change in the absence of extracellular ferroxidase activity in cells that do not express membrane GPI-Cp (De Domenico et al., 2007), as is the case in the neuroblastoma cell line we used.

We hypothesize that increases in oxidative stress in PD patients, both at neuronal and CSF levels, induce the reduction of extracellular ferroxidase activity through the oxidation both of membrane-bound and of soluble Cp; in turn, this reduction might contribute to the iron loading observed in SN (Oakley et al., 2007; Jin et al., 2011). The possibility that Cp plays a role in PD 
mandates the analysis of GPI-Cp expression and modifications on astrocyte, because this isoform is the predominant $\mathrm{Cp}$ in the brain and can, as we demonstrated, be modified by oxidative environment. Interestingly, GPI-Cp has been reported to be downmodulated by oxidative stress in astroglial cells, and as such to contribute to intracellular iron deposition (Tapryal et al., 2009).

In conclusion, our findings suggest that $\mathrm{Cp}$ oxidation, in soluble, and possibly in GPI-Cp forms, might play a role in the pathogenesis of PD by contributing to iron dismetabolism, and that $\mathrm{Cp}$ should possibly be taken into consideration as a putative target of antioxidant therapies (Kang et al., 2002). The putative pathogenic role of $\mathrm{Cp}$ is mirrored by variations in patient CSF Cp electrophoretic patterns, variations that, because they correlate with disease stage, can be considered as potential markers for the evaluation of oxidative damage in the CNS.

\section{References}

Baraj B, Cortina JL, Sastre A, Granados M (1998) Copper interference on spectrophotometric determination of iron and their simultaneous determination using bathophenantroline-disulfonic acid disodium salt. Fresenius J Anal Chem 360:263-265.

Bettegazzi B, Mihailovich M, Di Cesare A, Consonni A, Macco R, Pelizzoni I, Codazzi F, Grohovaz F, Zacchetti D (2011) beta-Secretase activity in rat astrocytes: translational block of BACE1 and modulation of BACE2 expression. Eur J Neurosci 33:236-243.

Bharucha KJ, Friedman JK, Vincent AS, Ross ED (2008) Lower serum ceruloplasmin levels correlate with younger age of onset in Parkinson's disease. J Neurol 255:1957-1962.

Boll MC, Sotelo J, Otero E, Alcaraz-Zubeldia M, Rios C (1999) Reduced ferroxidase activity in the cerebrospinal fluid from patients with Parkinson's disease. Neurosci Lett 265:155-158.

Boll MC, Alcaraz-Zubeldia M, Montes S, Rios C (2008) Free copper, ferroxidase and SOD1 activities, lipid peroxidation and $\mathrm{NO}(\mathrm{x})$ content in the CSF. A different marker profile in four neurodegenerative diseases. Neurochem Res 33:1717-1723.

Brewer GJ, Kanzer SH, Zimmerman EA, Celmins DF, Heckman SM, Dick R (2010) Copper and ceruloplasmin abnormalities in Alzheimer's disease. Am J Alzheimers Dis Other Demen 25:490-497.

Brooks BR (1994) El Escorial World Federation of Neurology criteria for the diagnosis of amyotrophic lateral sclerosis. Subcommittee on Motor Neuron Diseases/Amyotrophic Lateral Sclerosis of the World Federation of Neurology Research Group on Neuromuscular Diseases and the El Escorial "Clinical limits of amyotrophic lateral sclerosis" workshop contributors. J Neurol Sci 124 [Suppl]:96-107.

Cannistraci CV, Montevecchi FM, Alessio M (2009) Median-modified Wiener filter provides efficient denoising, preserving spot edge and morphology in 2-DE image processing. Proteomics 9:4908-4919.

Cannistraci CV, Ravasi T, Montevecchi FM, Ideker T, Alessio M (2010) Non-linear dimension reduction and clustering by minimun curvilinearity unfold neuropathic pain and tissue embryological classes. Bioinformatics 26:i531-i539.

Carrí MT, Ferri A, Cozzolino M, Calabrese L, Rotilio G (2003) Neurodegeneration in amyotrophic lateral sclerosis: the role of oxidative stress and altered homeostasis of metals. Brain Res Bull 61:365-374.

Choi SY, Kwon HY, Kwon OB, Eum WS, Kang JH (2000) Fragmentation of human ceruloplasmin induced by hydrogen peroxide. Biochimie 82:175-180.

Codazzi F, Di Cesare A, Chiulli N, Albanese A, Meyer T, Zacchetti D, Grohovaz F (2006) Synergistic control of protein kinase $\mathrm{C} \gamma$ activity by ionotropic and metabotropic glutamate receptor inputs in hippocampal neurons. J Neurosci 26:3404-3411.

Conti A, Ricchiuto P, Iannaccone S, Sferrazza B, Cattaneo A, Bachi A, Reggiani A, Beltramo M, Alessio M (2005) Pigment epithelium-derived factor is differentially expressed in peripheral neuropathies. Proteomics $5: 4558-4567$.

Conti A, Iannaccone S, Sferrazza B, De Monte L, Cappa S, Franciotta D, Olivieri S, Alessio M (2008) Differential expression of ceruloplasmin isoforms in the cerebrospinal fluid of amyotrophic lateral sclerosis patients. Proteomics Clin Appl 2:1628-1637.
Cozzi A, Rovelli E, Frizzale G, Campanella A, Amendola M, Arosio P, Levi S (2010) Oxidative stress and cell death in cells expressing L-ferritin variants causing neuroferritinopathy. Neurobiol Dis 37:77-85.

Dalle-Donne I, Giustarini D, Colombo R, Rossi R, Milzani A (2003) Protein carbonylation in human diseases. Trends Mol Med 9:169-176.

Dawson TM, Dawson VL (2003) Molecular pathways of neurodegeneration in Parkinson's disease. Science 302:819-822.

De Domenico I, Ward DM, di Patti MC, Jeong SY, David S, Musci G, Kaplan J (2007) Ferroxidase activity is required for the stability of cell surface ferroportin in cells expressing GPI-ceruloplasmin. EMBO J 26:2823-2831.

Duce JA, Tsatsanis A, Cater MA, James SA, Robb E, Wikhe K, Leong SL, Perez K, Johanssen T, Greenough MA, Cho HH, Galatis D, Moir RD, Masters CL, McLean C, Tanzi RE, Cappai R, Barnham KJ, Ciccotosto GD, Rogers JT, et al. (2010) Iron-export ferroxidase activity of beta-amyloid precursor protein is inhibited by zinc in Alzheimer's disease. Cell 142:857-867.

Fahn S (1987) Systemic therapy of dystonia. Can J Neurol Sci 14:528-532.

Götz ME, Double K, Gerlach M, Youdim MB, Riederer P (2004) The relevance of iron in the pathogenesis of Parkinson's disease. Ann N Y Acad Sci 1012:193-208.

Grimm S, Hoehn A, Davies KJ, Grune T (2011) Protein oxidative modifications in the ageing brain: consequence for the onset of neurodegenerative disease. Free Radic Res 45:73-88.

Harris ZL, Klomp LW, Gitlin JD (1998) Aceruloplasminemia: an inherited neurodegenerative disease with impairment of iron homeostasis. Am J Clin Nutr 67:972S-977S.

Hellman NE, Gitlin JD (2002) Ceruloplasmin metabolism and function. Annu Rev Nutr 22:439-458.

Hoehn MM, Yahr MD (1967) Parkinsonism: onset, progression, and mortality. Neurology 17:427-442.

Italian Neurological Society (2003) The diagnosis of Parkinson's disease. Neurol Sci 24 [Suppl 3]:S157-S164.

Jeong SY, David S (2003) Glycosylphosphatidylinositol-anchored ceruloplasmin is required for iron efflux from cells in the central nervous system. J Biol Chem 278:27144-27148.

Jin L, Wang J, Zhao L, Jin H, Fei G, Zhang Y, Zeng M, Zhong C (2011) Decreased serum ceruloplasmin levels characteristically aggravate nigral iron deposition in Parkinson's disease. Brain 134:50-58.

Kang JH, Kim KS, Choi SY, Kwon HY, Won MH (2001) Oxidative modification of human ceruloplasmin by peroxyl radicals. Biochim Biophys Acta 1568:30-36.

Kang JH, Kim KS, Choi SY, Kwon HY, Won MH, Kang TC (2002) Carnosine and related dipeptides protect human ceruloplasmin against peroxyl radical-mediated modification. Mol Cells 13:498-502.

Kohane IS, Kho AT, Butte AJ (2003) Microarrays for an integrative genomics. Cambridge, MA: MIT.

Litvan I, Halliday G, Hallett M, Goetz CG, Rocca W, Duyckaerts C, BenShlomo Y, Dickson DW, Lang AE, Chesselet MF, Langston WJ, Di Monte DA, Gasser T, Hagg T, Hardy J, Jenner P, Melamed E, Myers RH, Parker D Jr, Price DL (2007a) The etiopathogenesis of Parkinson disease and suggestions for future research. Part I. J Neuropathol Exp Neurol 66:251-257.

Litvan I, Chesselet MF, Gasser T, Di Monte DA, Parker D Jr, Hagg T, Hardy J, Jenner P, Myers RH, Price D, Hallett M, Langston WJ, Lang AE, Halliday G, Rocca W, Duyckaerts C, Dickson DW, Ben-Shlomo Y, Goetz CG, Melamed E (2007b) The etiopathogenesis of Parkinson disease and suggestions for future research. Part II. J Neuropathol Exp Neurol 66:329-336.

Loeffler DA, DeMaggio AJ, Juneau PL, Brickman CM, Mashour GA, Finkelman JH, Pomara N, LeWitt PA (1994) Ceruloplasmin is increased in cerebrospinal fluid in Alzheimer's disease but not Parkinson's disease. Alzheimer Dis Assoc Disord 8:190-197.

Lotharius J, Brundin P (2002) Pathogenesis of Parkinson's disease: dopamine, vesicles and alpha-synuclein. Nat Rev Neurosci 3:932-942.

Madsen E, Gitlin JD (2007) Copper and iron disorders of the brain. Annu Rev Neurosci 30:317-337.

McKhann G, Drachman D, Folstein M, Katzman R, Price D, Stadlan EM (1984) Clinical diagnosis of Alzheimer's disease: report of the NINCDSADRDA Work Group under the auspices of Department of Health and Human Services Task Force on Alzheimer's Disease. Neurology 34:939-944.

Merle U, Tuma S, Herrmann T, Muntean V, Volkmann M, Gehrke SG, Stremmel W (2010) Evidence for a critical role of ceruloplasmin oxidase 
activity in iron metabolism of Wilson disease gene knockout mice. J Gastroenterol Hepatol 25:1144-1150.

Mittal B, Doroudchi MM, Jeong SY, Patel BN, David S (2003) Expression of a membrane-bound form of the ferroxidase ceruloplasmin by leptomeningeal cells. Glia 41:337-346.

Moos T, Rosengren Nielsen T, Skjørringe T, Morgan EH (2007) Iron trafficking inside the brain. J Neurochem 103:1730-1740.

Muller T, Hefter H, Hueber R, Jost WH, Leenders KL, Odin P, Schwarz J (2004) Is levodopa toxic? J Neurol 251 [Suppl 6]:VI/44-46.

Musci G, Bonaccorsi di Patti MC, Fagiolo U, Calabrese L (1993) Age-related changes in human ceruloplasmin. Evidence for oxidative modifications. J Biol Chem 268:13388-13395.

Oakley AE, Collingwood JF, Dobson J, Love G, Perrott HR, Edwardson JA, Elstner M, Morris CM (2007) Individual dopaminergic neurons show raised iron levels in Parkinson disease. Neurology 68:1820-1825.

Patel BN, Dunn RJ, Jeong SY, Zhu Q, Julien JP, David S (2002) Ceruloplasmin regulates iron levels in the CNS and prevents free radical injury. J Neurosci 22:6578-6586.

Pelizzoni I, Macco R, Morini MF, Zacchetti D, Grohovaz F, Codazzi F (2011) Iron handling in hippocampal neurons: activity-dependent iron entry and mitochondria-mediated neurotoxicity. Aging Cell 10:172-183.

Rathore KI, Kerr BJ, Redensek A, López-Vales R, Jeong SY, Ponka P, David S
(2008) Ceruloplasmin protects injured spinal cord from iron-mediated oxidative damage. J Neurosci 28:12736-12747.

Ruggeri G, Santambrogio P, Bonfiglio F, Levi S, Bugari G, Verardi R, Cazzola M, Invernizzi R, Zambelli LM, Albertini A (1992) Antibodies for denatured human $\mathrm{H}$-ferritin stain only reticuloendothelial cells within the bone marrow. Br J Haematol 81:118-124.

Tapryal N, Mukhopadhyay C, Das D, Fox PL, Mukhopadhyay CK (2009) Reactive oxygen species regulate ceruloplasmin by a novel mRNA decay mechanism involving its $3^{\prime}$-untranslated region: implications in neurodegenerative diseases. J Biol Chem 284:1873-1883.

Texel SJ, Xu X, Harris ZL (2008) Ceruloplasmin in neurodegenerative diseases. Biochem Soc Trans 36:1277-1281.

Tórsdóttir G, Sveinbjörnsdóttir S, Kristinsson J, Snaedal J, Jóhannesson T (2006) Ceruloplasmin and superoxide dismutase (SOD1) in Parkinson's disease: a follow-up study. J Neurol Sci 241:53-58.

Vassiliev V, Harris ZL, Zatta P (2005) Ceruloplasmin in neurodegenerative diseases. Brain Res Brain Res Rev 49:633-640.

Youdim MB, Stephenson G, Ben Shachar D (2004) Ironing iron out in Parkinson's disease and other neurodegenerative diseases with iron chelators: a lesson from 6-hydroxydopamine and iron chelators, desferal and VK28. Ann N Y Acad Sci 1012:306-325. 